\title{
Typical Crossmodal Numerosity Perception in Preterm Newborns
}

\author{
Giovanni Anobile ${ }^{1, * * *}$, Maria C. Morrone ${ }^{2, * *}$, Daniela Ricci ${ }^{3,4}$, \\ Francesca Gallini $^{4}$, Ilaria Merusi ${ }^{5, * * * *}$ and Francesca Tinelli ${ }^{6, * * * * *}$ \\ ${ }^{1}$ Department of Neuroscience, Psychology, Pharmacology and Child Health, University of \\ Florence, 50135 Florence, Italy \\ ${ }^{2}$ Department of Translational Research on New Technologies in Medicine and Surgery, \\ University of Pisa, 56123 Pisa, Italy \\ ${ }^{3}$ National Centre of Services and Research for Prevention of Blindness and Rehabilitation of \\ Visually Impaired, Rome, Italy \\ ${ }^{4}$ Department of Pediatrics, Catholic University of the Sacred Heart, Rome, Italy \\ ${ }^{5}$ Division of Pediatrics, Versilia Hospital, Italy \\ ${ }^{6}$ Department of Developmental Neuroscience, IRCCS Fondazione Stella Maris, 56128 \\ Calambrone, Pisa, Italy
}

Received 14 July 2020; accepted 7 April 2021

\begin{abstract}
Premature birth is associated with a high risk of damage in the parietal cortex, a key area for numerical and non-numerical magnitude perception and mathematical reasoning. Children born preterm have higher rates of learning difficulties for school mathematics. In this study, we investigated how preterm newborns (born at 28-34 weeks of gestation age) and full-term newborns respond to visual numerosity after habituation to auditory stimuli of different numerosities. The results show that the two groups have a similar preferential looking response to visual numerosity, both preferring the incongruent set after crossmodal habituation. These results suggest that the numerosity system is resistant to prematurity.
\end{abstract}

\section{Keywords}

preterm, numerosity perception, numerical cognition, neonatal cognition, newborns, crossmodal perception

\footnotetext{
* To whom correspondence should be addressed. E-mail: giovanni.anobile@unifi.it

** ORCID: 0000-0003-2796-0661

*** ORCID: 0000-0002-1025-0316

**** ORCID: 0000-0003-0822-6197

****** ORCID: 0000-0002-7755-5114
} 


\section{Introduction}

According to the World Health Organization (World Health Organization, 2018), every year around 15 million babies are born preterm (i.e., $<37$ weeks of gestation age), with 1 million dying due to complications of preterm birth and many survivors developing lifetime difficulties. Prematurity in general, and extreme prematurity in particular ( $<32$ weeks of gestation), is a wellknown high-risk factor for atypical neurological development, especially for injuries within parietal areas (Isaacs et al., 2001; Padilla et al., 2015; Volpe, 2009).

Premature children often show poor performance in a variety of parietalmediated abilities such as the visual perception of motion (Braddick et al., 2003; Guzzetta et al., 2009; MacKay et al., 2005; Taylor et al., 2009a), the perception of intervals duration (Tinelli et al., 2015), the ability to deploy visual-spatial attention (Anderson et al., 2011; Guzzetta et al., 2006; Kooiker et al., 2019; Tinelli et al., 2015; van de Weijer-Bergsma et al., 2008), amongst other abilities (for a review see Atkinson and Braddick, 2007). Beyond the perceptual deficits, prematurity is also a risk factor for academic difficulties, particularly in mathematics (Aarnoudse-Moens et al., 2009, 2011; Isaacs et al., 2001; Taylor et al., 2009b; Twilhaar et al., 2018).

In the last few years there has been increasing scientific interest in the neurocognitive foundations of numerical cognition. It has been suggested that a prerequisite for a typical development of math abilities is a well-functioning preverbal system to perceive numerosity (Butterworth, 2018; Butterworth et al., 2011; Halberda et al., 2008; Piazza, 2010; Price et al., 2007). Numerosity perception refers to the ability to estimate, quickly but roughly, the numerical quantity of objects or events, accomplished without serial counting (Dehaene, 2011). Importantly, performance on numerosity tasks often correlates with math abilities (Halberda et al., 2008; Starr et al., 2013), strongly engages parietal areas (Butterworth and Walsh, 2011; Castelli et al., 2006; Holloway and Ansari, 2010; Nieder and Dehaene, 2009) and is often impaired in people with developmental dyscalculia (Anobile et al., 2018a; Butterworth, 2018; Cicchini et al., 2019; Mazzocco et al., 2011; Piazza et al., 2010).

Numerosity covaries with many nonnumerical magnitudes and stimulus properties (Bueti and Walsh, 2009) like texture, size and density. In addition, numerosity and magnitude estimation tasks are very difficult to distinguish by manipulation of the number of items (Dakin et al., 2011; Gebuis and Reynvoet, 2012; Gebuis et al., 2016). Building on this and other evidence, a recent influential work suggests that the nature of the "number sense" should be reconsidered since it should be better interpreted as a 'magnitude sense' (Leibovich et al., 2017). This issue is still largely debated, particularly in studies 
involving newborns, where experiments cannot scan many stimulus parameters and need to be limited by the short allocation time of the attentive and cognitive resources (de Hevia et al., 2017; Leibovich et al., 2017).

Also, the link between numerosity perception and the development of symbolic arithmetical skills is far from clear, with some evidence pointing to no numerosity deficit in dyscalculia (De Smedt and Gilmore, 2011; Landerl and Kölle, 2009; Rousselle and Noël, 2007; Szucs et al., 2013), null or weak correlations among neurotypicals participants (Chen and Li, 2014; Schneider et al., 2017) and no clear causal link between the two performances. Recent evidence converges to suggest that numerosity and symbolic numbers should be considered as independent constructs (Núñez, 2017). The developmental stage could also be crucial in modulating the link between numerosity perception and symbolic numeracy. While during early developmental stages non-symbolic quantities and numbers may be more strongly linked, probably mapping on to each other, in adults this mapping might become weaker or annulled (Anobile et al., 2018b; Lyons et al., 2012).

As with the perception of numerosity, many non-numerical continuous features like quantities and symbolic arithmetical tasks largely involves parietal areas (Bueti and Walsh, 2009; Castaldi et al., 2019; Harvey and Dumoulin, 2017; Harvey et al., 2013, 2015; Piazza and Eger, 2016) that mature slowly with age, making it interesting to measure the functionality of the system underlying magnitude perception in newborns. In this work we compared typical term newborns with preterm newborns, a population at high risk for deficits in the key brain areas subtending this function and characterized by a relatively high rate of arithmetic learning difficulties. Investigating numerosity representation in preterm babies, particularly at the earliest stage of life, could provide indirect information about the early functionality of brain areas involved in mathematical learning, opening up the possibility of developing targeted and effective intervention strategies.

To this aim, we adapted a crossmodal behavioural test developed by Izard and colleagues (Coubart et al., 2014; Izard et al., 2009). In their study, fullterm newborns ( $0-4$ days) were stimulated with sound sequences containing a fixed number of syllables (sound containing repetition of 12 or four syllables). Newborns were then sequentially presented with visuo-spatial arrays containing 12 or four images, while the sound sequences still played in the background. In this respect the paradigm is different from the classical habituation design, where the habituation stimulus is not presented in overlap with the test stimulus. With this paradigm the authors consistently observed that newborns looked longer when the visual arrays matched the auditory stimulation in numerosity, suggesting that human newborns are equipped with the ability to recognize numerical differences between senses and stimuli formats (sequential-auditory/spatial-visual). 
This technique is simple and well suited for use with preterm newborns to assess whether numerosity perception is impaired at birth. In addition, given its multisensory nature it is also informative on the role of prematurity on the ability to combine information across senses (vision and audition in this case).

\section{Material and Methods}

\subsection{Methods}

Newborns were recruited directly inside the maternity ward, with the authorization of the director of the maternity department at Neonatal Unit, Catholic University in Rome and at Pediatrics and Neonatology Division, Versilia Hospital in Viareggio. The research was approved by the Institutional Review Board of Stella Maris Scientific Institute in Pisa and informed consent was obtained from parents before testing.

\subsection{Power Analyses}

Sample size was calculated with a-priori Power analyses using G*Power software (version 3.1; Faul et al., 2007). As the main goal of the current experiment was to detect a numerosity habituation effect in full-term and preterm newborns, the Power analyses aimed to calculate the required sample size of each group to reliably detect a difference between two dependent means (onetailed paired $t$-test). The means here refers to the average looking time at the congruent and the incongruent visual stimuli. The effect size was estimated from Izard et al. (2009) taking the parameters from the same experimental condition used in the current study: the looking time at four versus 12 elements $(d=1.12)$. With an $\alpha=0.05$ and a Power of 0.8 , the analyses revealed a required sample size of seven (lower than that recruited here, 12 for each group, see below).

\subsection{Participants}

Thirty-nine babies (20 preterm and 19 full-term newborns) were recruited, but 15 of them (eight preterm and seven full-term) were not able to conclude the task (mainly because they fell asleep or cried). The final sample (Table 1) was composed of 12 preterm (seven females; gestational age range: $28^{+6}-34$ weeks; range of weight: $1190-2100 \mathrm{~g}$ ) and 12 newborns born at term (gestational age range: $38^{+5}-41^{+6}$ weeks; range of weight: $2740-4110 \mathrm{~g}$, see Table 1). Six preterm babies were tested at around 35 weeks of gestational age (range $34^{+5}-35^{+2}$ ) after exposure to external environment of only a few days (range: 8-19 days; mean: 15 days); six other preterm babies were tested at equivalent term age (range: $38-40^{+3}$ ) after exposure to external environment of a longer period (range: 59-78 days; mean: 65 days). Full-term newborns were tested within three days after birth. 
Table 1.

Sample demographical characteristics

\begin{tabular}{|c|c|c|c|c|c|}
\hline Subjects & Date of birth & $\begin{array}{l}\text { Gestational age } \\
\text { (weeks + days) }\end{array}$ & $\begin{array}{l}\text { Birthweight } \\
\text { (grams) }\end{array}$ & $\begin{array}{c}\text { Gestational age } \\
\text { at test } \\
\text { (weeks + days) }\end{array}$ & $\begin{array}{c}\text { Chronological } \\
\text { age } \\
\text { (days) }\end{array}$ \\
\hline \multicolumn{6}{|l|}{ Preterm } \\
\hline $\mathrm{S} 1$ & $14 / 03 / 2013$ & $32+5$ & 1460 & 35 & 17 \\
\hline $\mathrm{S} 2$ & 01/07/2013 & $32+5$ & 1490 & 35 & 16 \\
\hline $\mathrm{S} 3$ & 01/07/2013 & $32+5$ & 1700 & 35 & 16 \\
\hline S4 & $13 / 07 / 2013$ & $32+3$ & 1300 & 35 & 19 \\
\hline S5 & $22 / 07 / 2013$ & $32+4$ & 1920 & $34+5$ & 17 \\
\hline S6 & $21 / 07 / 2013$ & $28+6$ & 1190 & 40 & 78 \\
\hline S7 & 09/09/2013 & $31+6$ & 1700 & $40+3$ & 70 \\
\hline S8 & $10 / 10 / 2013$ & 34 & 2100 & 35 & 8 \\
\hline S9 & $13 / 10 / 2013$ & $30+5$ & 1590 & 39 & 64 \\
\hline S10 & $18 / 10 / 2013$ & $29+6$ & 1380 & 38 & 59 \\
\hline $\mathrm{S} 11$ & $18 / 10 / 2013$ & $29+6$ & 1320 & 38 & 59 \\
\hline $\mathrm{S} 12$ & $18 / 10 / 2013$ & $29+6$ & 1475 & 38 & 59 \\
\hline \multicolumn{6}{|l|}{ Full-term } \\
\hline $\mathrm{S} 1$ & $27 / 01 / 15$ & $41+4$ & 4110 & $41+4$ & 0 \\
\hline $\mathrm{S} 2$ & $26 / 01 / 15$ & $39+2$ & 4100 & $39+3$ & 1 \\
\hline $\mathrm{S} 3$ & $27 / 01 / 15$ & $41+2$ & 3340 & $39+4$ & 1 \\
\hline S4 & $09 / 02 / 15$ & $40+4$ & 2870 & $40+6$ & 2 \\
\hline S5 & $08 / 02 / 15$ & $38+6$ & 2740 & $39+2$ & 3 \\
\hline S6 & $21 / 02 / 15$ & $41+3$ & 3200 & $41+6$ & 3 \\
\hline S7 & $02 / 03 / 15$ & 39 & 2980 & $39+1$ & 1 \\
\hline S8 & $23 / 06 / 15$ & $40+3$ & 3270 & $40+3$ & 1 \\
\hline S9 & $24 / 03 / 15$ & $40+3$ & 3810 & $40+3$ & 0 \\
\hline $\mathrm{S} 10$ & $13 / 07 / 15$ & $38+2$ & 2820 & $38+6$ & 1 \\
\hline S11 & $13 / 07 / 15$ & $38+5$ & 3460 & $38+5$ & 1 \\
\hline $\mathrm{S} 12$ & $13 / 07 / 15$ & $40+2$ & 3640 & $40+3$ & 1 \\
\hline
\end{tabular}

Inclusion criteria were absence of auditory disorders (we enrolled only neonates with a response of 'pass bilateral' to auditory screening) and absence of visual disorders due to retinopathy of prematurity (ROP) more than stage II (in our sample only one subject had a ROP II).

More details about Apgar indexes at 5', presence or not of breathing distress, ultrasounds and complications at birth are reported in Table 2.

\subsection{Task and Procedures}

Participants were tested in the hospital where they were born. The newborns were seated in an infant seat, $\approx 60 \mathrm{~cm}$ from a 22-inch monitor, and their gaze and overall orientation were continuously recorded by a high-sensitivity camera positioned over the visual display. The task was a modified version of that used by Izard et al. (2009) and is depicted in Fig. 1. Each infant was 
Table 2.

Sample clinical characteristics

\begin{tabular}{|c|c|c|c|c|c|}
\hline Subjects & $\begin{array}{c}\text { Apgar } \\
\text { Index (5') }\end{array}$ & Distress & Ultrasound & ROP & $\begin{array}{c}\text { Complications } \\
\text { at birth }\end{array}$ \\
\hline \multicolumn{6}{|l|}{ Preterm } \\
\hline S1 & 9 & Yes & $\begin{array}{l}\text { Persistent } \\
\text { PVE }\end{array}$ & No & $\mathrm{I}, \mathrm{A}, \mathrm{ADP}$ \\
\hline $\mathrm{S} 2$ & 10 & Yes & $\begin{array}{l}\text { Diffuse } \\
\text { PVE }\end{array}$ & No & $\mathrm{I}, \mathrm{A}$ \\
\hline S3 & 7 & Yes & $\begin{array}{l}\text { Diffuse } \\
\text { PVE }\end{array}$ & No & A \\
\hline S4 & 9 & No & $\begin{array}{l}\text { Persistent } \\
\text { PVE }\end{array}$ & No & I, PSVT \\
\hline S5 & 9 & No & Light PVE & No & I, T \\
\hline S6 & 9 & Yes & Normal & No & I, VSD \\
\hline S7 & 9 & No & Light PVE & No & I \\
\hline S8 & 9 & No & Normal & No & I \\
\hline S9 & 8 & No & Light PVE & No & I \\
\hline S10 & 9 & Yes & Normal & No & I, PD \\
\hline S11 & 9 & No & Normal & No & $\mathrm{I}, \mathrm{SA}, \mathrm{S}$ \\
\hline $\mathrm{S} 12$ & 10 & No & Normal & ROP II & $\mathrm{I}, \mathrm{A}, \mathrm{SA}$ \\
\hline \multicolumn{6}{|l|}{ Full-term } \\
\hline S1 & 10 & No & No & No & None \\
\hline $\mathrm{S} 2$ & 10 & No & No & No & None \\
\hline $\mathrm{S} 3$ & 8 & No & No & No & None \\
\hline $\mathrm{S} 4$ & 10 & No & No & No & None \\
\hline S5 & 10 & No & No & No & None \\
\hline S6 & 10 & No & No & No & None \\
\hline S7 & 8 & No & No & No & None \\
\hline S8 & 9 & No & No & No & None \\
\hline S9 & 10 & No & No & No & None \\
\hline S10 & 9 & No & No & No & None \\
\hline S11 & 10 & No & No & No & None \\
\hline S12 & 8 & No & No & No & None \\
\hline
\end{tabular}

$\mathrm{ROP}=$ retinopathy of prematurity; $\mathrm{PVE}=$ periventricular echogenicity; $\mathrm{I}=$ icterus; $\mathrm{A}=$ anaemia; $\mathrm{ADP}=$ arterial ductus patency; PSVT $=$ paroxysmal supraventricular tachycardia; $\mathrm{T}=$ tachycardia $; \mathrm{VSD}=$ ventricular septal defect $\mathrm{PD}=$ platelet disorders $; \mathrm{SA}=$ sleep apneas; $\mathrm{S}=$ sepsis.

stimulated with an auditory stream consisting of sequences of syllables (one minute), each repeated four or twelve times (played by speakers located below the screen). During this phase, the screen was black. After this phase (one minute), the newborns were presented with two consecutive test images (while the auditory stimulus continued to play), one congruent in numerosity and the other incongruent for a maximum of two minutes or until the infant diverted 


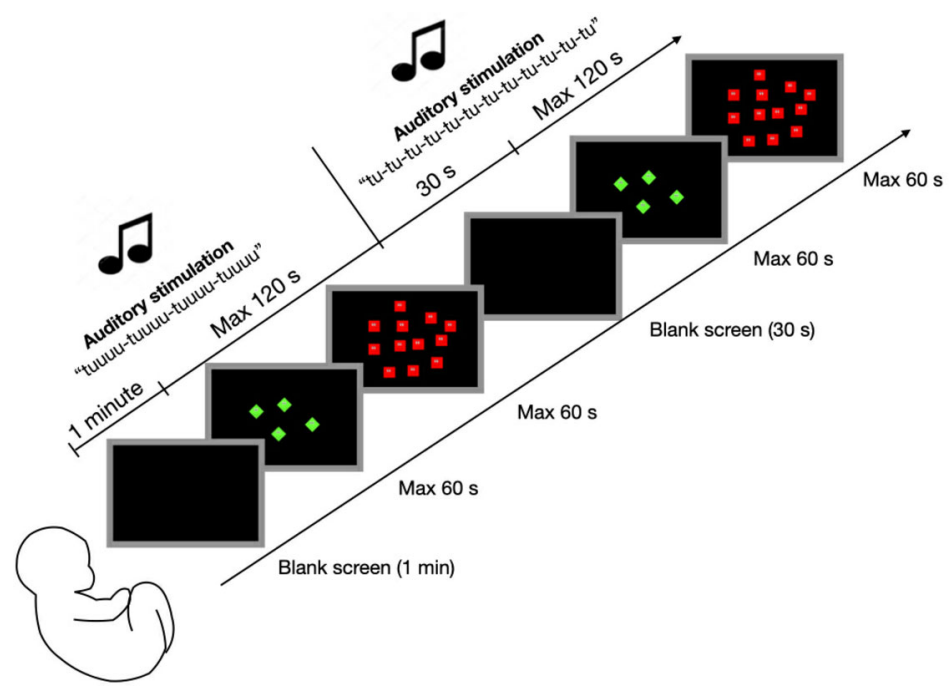

Figure 1. Illustration of the procedure. Along the entire experiment, infants were stimulated with auditory sequences containing a fixed number of sounds (4 or 12 syllables). In the first one minute of auditory stimulation the screen remained black, then two consecutive images were displayed containing the same or a different number of items ( 4 or 12 in a random order). Then a second block of trials started, with the auditory sequences containing the opposite number of sounds compared to the first block and with the habituation lasting $30 \mathrm{~s}$ instead of one minute.

their gaze from the stimulus for $2 \mathrm{~s}$ (first block hereafter). After this phase, the screen turned black again and a second habituation phase started (second block). This second auditory habituation contained the opposite numerosity relative to the first habituation phase (twelve if the first contained four and vice versa) and lasted $30 \mathrm{~s}$ instead of one minute (Fig. 1). This second habituation was again followed by two test trials, one congruent and one incongruent (random order across trials). Table 3 show the four habituation test conditions and the overall number of tests for each group. The conditions were balanced across participants except for a small imbalance between $\mathrm{C} 2$ and $\mathrm{C} 3$, reflecting the imbalance between groups of the infants that did not complete the test (eight preterm and seven full-term infants). The images stayed on the screen until the infant looked away for $2 \mathrm{~s}$, or after $60 \mathrm{~s}$ of looking. We used a shorter habituation time in the second block given that the attentional allocation of preterms is very short and a longer exposition would decrease the possibility of acquiring the visual looking time. With this shorter duration we were able to record the second block data in all except one preterm infant.

Looking times were recorded online by a trained observer observing the child from about $60 \mathrm{~cm}$ behind the screen and hidden by a black cloth with an eye slit. This online score was to detect the time that the baby looked at the screen. To this aim, the operator kept the space-bar pressed until the infant 
Table 3.

Condition order and sample size

\begin{tabular}{lccc}
\hline $\begin{array}{l}\text { Condition } \\
\mathrm{h}=\text { auditory hab, } \\
\mathrm{t}=\text { visual num }\end{array}$ & $\begin{array}{c}\text { Preterms } \\
\text { total }(n \text { first block, } \\
n \text { second block) }\end{array}$ & $\begin{array}{c}\text { Full terms } \\
n \text { total }(n \text { first block, } \\
n \text { second block })\end{array}$ & Total tests \\
\hline C1: h12 t4 t12 & $7(3,4)$ & $5(2,3)$ & 12 \\
C2: h4 t12 t4 & $4(2,2)$ & $7(4,3)$ & 11 \\
C3: h4 t4 t12 & $7(4,3)$ & $6(4,2)$ & 13 \\
C4: h12 t12 t4 & $6(3,3)$ & $6(2,4)$ & 12 \\
\hline
\end{tabular}

looked away for $2 \mathrm{~s}$; release of the button automatically triggered the disappearance of the current stimulus and the appearance of the new visual stimulus (or the beginning of the second habituation phase). An additional scoring of slow-motion videos was performed offline by the same experimenter and another observer also blind to experimental conditions. Since the duration of the visual stimuli was determined by the operator recording online, the purpose of this second scoring was to confirm that the stimuli were correctly maintained on the screen as long as the children did not look away from the screen for $2 \mathrm{~s}$, a criterion which was always reached.

We used similar visual and auditory stimuli as in Coubart's research (Coubart et al., 2014; Izard et al., 2009). Auditory streams were built from eight different syllables of variable duration. Sequences were equated in duration across numbers so that each syllable was shorter for the larger number. The average duration of syllable sequences varied between $2.9 \mathrm{~s}$ and $4.4 \mathrm{~s}$, and successive sequences were separated by a variable silent interval of 1-3 s duration. Images were arrays of identical geometrical shapes (brightly coloured, with facial features: eyes and mouth).

In the test images, the items size and density were equated across numbers, such that the summed luminance and total surface occupied by the array increased with number. Four different shapes and colours were used across the four test images. To sustain attention, images moved horizontally (stroboscopic displacement at $1 \mathrm{~s}$, unsynchronized with the onset of auditory sequences). The full images were $14-25 \mathrm{~cm}$ in size and the size of each individual object was $2.8 \mathrm{~cm}$ (corresponding to 2.66 degrees of visual angle).

\section{Results}

\subsection{General Performance}

The general performance, namely the looking time averaged across the two trials blocks (four visual stimuli) and the two auditory habituation conditions, are plotted in Fig. 2. 

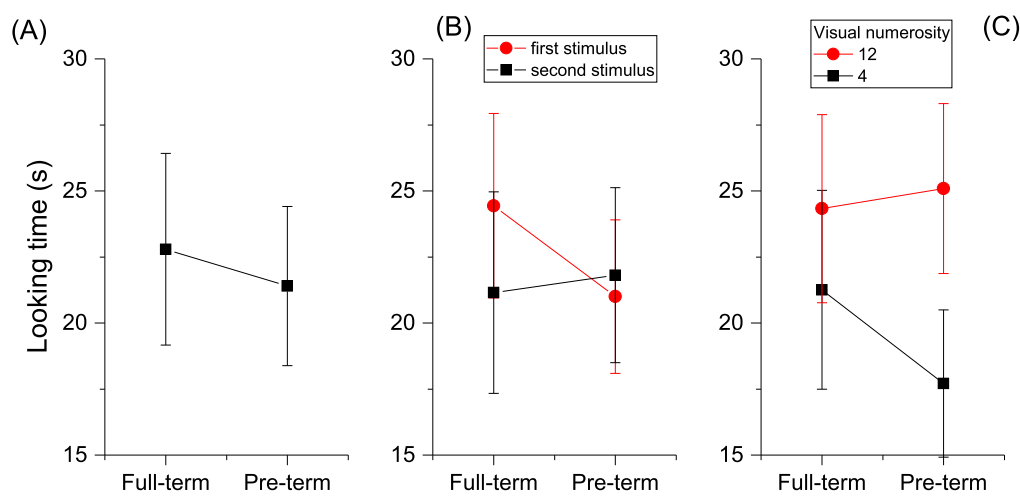

Figure 2. General looking behaviour across the first and second block of trials. (A) Betweensubject's average looking time independently from order presentation, visual numerosity and auditory habituation. (B) Time spent looking at the first and second visual stimulus independently from numerosity and habituation. (C) Time spent looking at numerosity 4 and 12 independently from stimuli order and habituation. Error bars reports \pm 1 s.e.m.

Considering all newborns together, the overall looking time was 44.7 (SD 16.34) s, about $37 \%$ of the total permitted duration (120 s), confirming that the paradigm was well able to capture the infant's attention. More importantly, preterm average looking time was $21.4 \mathrm{~s}$ (SD 14.79), similar to that of fullterms (22.79 s, SD 17.82), suggesting that the task engaged the two groups similarly (Fig. 2A).

As shown in Fig. 2B, the two groups also spent a similar amount of time looking at the first (preterm: $\mathrm{M}=21.80, \mathrm{SD}=15.87 \mathrm{~s}$; full-term: $\mathrm{M}=24.4$, $\mathrm{SD}=17.14 \mathrm{~s}$ ) and second visual stimuli (preterm: $\mathrm{M}=21.15, \mathrm{SD}=18.7 \mathrm{~s}$; full-term: $\mathrm{M}=21.8 \mathrm{SD}=15.87 \mathrm{~s}$ ) of the sequences. Similarly, the two groups spent a slightly higher time looking at the more numerous visual stimulus $(\mathrm{N} 12$, preterm: $\mathrm{M}=25.09, \mathrm{SD}=15.458 \mathrm{~s}$; full-term: $\mathrm{M}=24.33, \mathrm{SD}=$ $17.44 \mathrm{~s} ; \mathrm{N} 4$, preterm: $\mathrm{M}=17.71, \mathrm{SD}=13.428 \mathrm{~s}$; full-term: $\mathrm{M}=21.257$, $\mathrm{SD}=18.445 \mathrm{~s}$; Fig. 2C).

To quantify the effects, we ran an ANOVA with looking time (raw looking time at each visual stimulus) as the dependent variable and groups (two levels: preterm, full-term), visual numerosity (two levels: N4, N12) and stimulus order (two levels: first, second) as independent variables. Results confirmed a similar behaviour across groups, $\left(F_{1,86}=0.156, p=0.694, \eta^{2}=0.002\right)$ and across numerosity $\left(F_{1,86}=2.47, p=0.119, \eta^{2}=0.027\right)$ as well as for the stimulus order $\left(F_{1,86}=0.401, p=0.528, \eta^{2}=0.004\right)$. Moreover, the groupby-numerosity $\left(F_{1,86}=0.362, p=0.549, \eta^{2}=0.004\right)$ and group-by-order $\left(F_{1,86}=0.154, p=0.696, \eta^{2}=0.002\right)$ interactions were not statistically significant. Overall, these results suggest a very similar looking behaviour between preterm and full-term newborns. 
The same analyses were then performed considering the first and the second block of trials separately. For the first block, the main effect of group $\left(F_{1,40}=0.007, p=0.933, \eta^{2} \leqslant 0.001\right)$, of visual numerosity $\left(\mathrm{F}_{1,40}=1, p=\right.$ $\left.0.324, \eta^{2}=0.024\right)$, as well as the effect of stimuli order $\left(F_{1,40}=0.4, p=\right.$ $0.531, \eta^{2}=0.009$ ) were not statistically significant. The group-by-numerosity $\left(F_{1,40}=0.534, p=0.469, \eta^{2}=0.013\right)$ and group-by-order $\left(F_{1,40}=0.004\right.$, $\left.p=0.951, \eta^{2}<0.001\right)$ interactions were also not statistically significant. The same pattern of results, considering only the second block of trials with the main effect of group $\left(F_{1,38}=0.19, p=0.665, \eta^{2}=0.004\right)$, of visual numerosity $\left(F_{1,38}=1.48, p=0.231, \eta^{2}=0.035\right)$, stimulus order $\left(F_{1,38}=\right.$ $\left.0.056, p=0.813, \eta^{2}=0.001\right)$, as well as the group-by-numerosity $\left(F_{1,38}=\right.$ 2.53, $\left.p=0.12, \eta^{2}=0.059\right)$ and group-by-order interactions $\left(F_{1,38}=0.09\right.$, $p=0.765, \eta^{2}=0.002$ ), was found to be not statistically significant. These results confirmed a very similar looking behaviour between preterm and fullterm newborns even within each block of trials.

\subsection{Looking Behaviour as a Function of Auditory Habituation}

After establishing that the two groups had a similar looking behaviour in this task, we focused on the effect of the auditory habituation.

We first analysed the data considering both blocks of trials together (Fig. 3A).

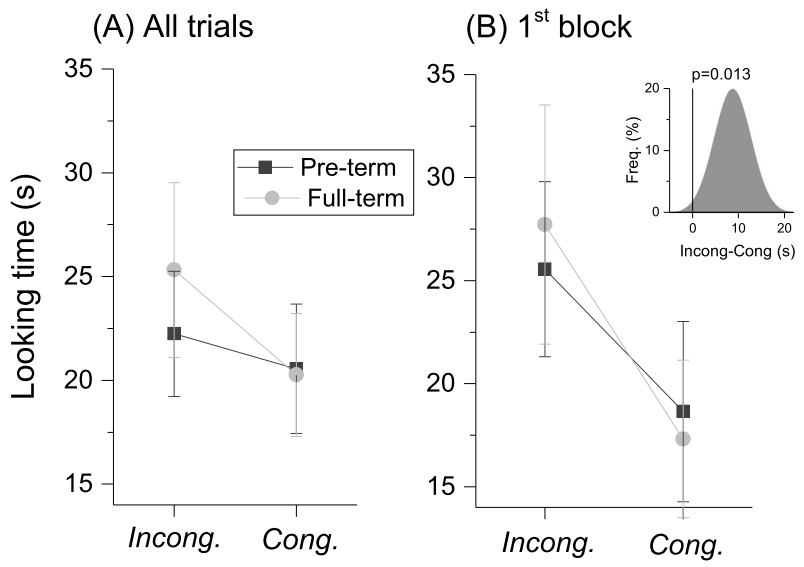

Visual Stimulus

Figure 3. Numerosity cross-modal habituation effect. Looking time at the visual stimulus containing the same (congruent) or a different (incongruent) numerosity relative to the ongoing auditory stream averaging all trials together (A) or considering only the first block of two images (B). Error bars reports \pm 1 s.e.m. The insert in (B) report the bootstrap frequency distribution of the preferential looking index, across all participants. The $p$ value refers to bootstrap sign-test. 
Preterm and full-term looked at the congruent visual stimulus for $\sim 20 \mathrm{~s}$ (preterm: $\mathrm{M}=20.563, \mathrm{SD}=14.76$; full-terms: $\mathrm{M}=20.563, \mathrm{SD}=14.5$ ) slightly less compared to the incongruent stimulus, where preterms looked for $22.246(\mathrm{SD}=15.10)$ while full-terms, for $25.32(\mathrm{SD}=20.63)$. However, the difference between the time spent looking at the incongruent and the congruent stimulus (preferential looking index hereafter) was not significantly different from zero for both groups (preterm: $t_{22}=0.41 p=0.343$, full-term: $t_{23}=$ $1.274 ; p=0.10$, one-tailed) and also considering the sample as a whole $\left(t_{46}=\right.$ $1.183, p=0.12$, one-tailed).

In order to further investigate this, we ran the same analyses but averaging, for each participant, the preferential looking indexes obtained in the first and second block of trials. The results of these analyses confirmed the previous one (preterm: $t_{10}=0.496, p=0.315$; full-term: $t_{11}=1.415, p=0.092$; sample as a whole: $t_{22}=1.394, p=0.09$, one-tailed).

\subsection{Habituation Effect in the First Block of Trials}

As detailed in the Methods section, this experiment was designed to have two consecutives, 'opposite' and with different durations of the auditory habituation phases. After the first 60-s auditory habituation phase, and the end of the two visual trials, a second auditory habituation started. This second habituation lasted half as long as the first (30 s) and contained the opposite auditory numerosity. Probably, this second block induced a dishabituation to the first and then a new habituation to the second auditory stimulus in the opposite direction. Analysing both blocks of trials together may, therefore, have masked an habituation effect in the first block of trials.

For this reason, we ran a second analysis, this time considering only the first block (60 s of auditory habituation followed by two visual stimuli). The newborns, as a whole group, looked more at the incongruent stimuli: the average looking time for the incongruent visual stimuli was $26.75(\mathrm{SD}=17.3) \mathrm{s}$, while $17.98(\mathrm{SD}=13.9) \mathrm{s}$ for the congruent. The difference between the time spent looking at the incongruent and the congruent stimuli was statistically different from zero $\left(t_{23}=2.125, p=0.022\right.$, one-tailed, Cohens's $d=0.434, \mathrm{BF}_{10}=$ 2.8).

To confirm this result, we ran a nonparametric bootstrap analysis that does not rely on a-priori assumptions about the distribution (Efron and Tibshirani, 1993). On each of 10000 bootstrap iterations we resampled (with re-emission) the preferential looking indexes of the individual subjects and calculated the mean effect. The analyses confirmed a statistically significant difference from zero $(p=0.013)$ of the mean, with newborns looking more at the incongruent visual stimulus (see Fig. 3B, insert).

When reducing the sample size by splitting the full sample into preterm and full-term, the trend of results was similar, with lower $p$-values and effect size: 
preterm (congruent: $\mathrm{M}=18.64, \mathrm{SD}=15.17$; incongruent: $\mathrm{M}=25.76, \mathrm{SD}=$ $14.83 ; t_{11}=1.232, p=0.12$, one-tailed, Cohens's $d=0.36$ ) and full-term (congruent $\mathrm{M}=17.32, \mathrm{SD}=13.21$, incongruent $\mathrm{M}=27.71, \mathrm{SD}=20.10$; $t_{11}=1.7, p=0.058$, one-tailed, Cohens's $d=0.492$ ).

To evaluate whether the two groups had a different amount of preferential looking effect, we ran an ANOVA on the preferential looking index (the difference between the time spent looking at the incongruent and the congruent stimulus) entering the group (preterm, full-term) as the independent variable. The analyses revealed no effect between the groups $\left(F_{1,22}=0.153, p=0.699\right.$, $\left.\eta^{2}=0.007\right)$ confirming a similar habituation effect across groups.

Figure 4 shows single- subject data obtained in the first block of trials as the time spent looking at numerosity four or twelve while concurrently stimulated by bursts of four (black) or twelve (blue) auditory, separately for the two groups (squares preterm, circles full-term). Despite the intersubjective variability, it is evident that, on average (bigger symbols), the two groups behave very similarly, preferring the visually incongruent stimuli.

Finally, we also looked at the second block of trials. Results showed that in the second block the newborns (as a whole group) looked similarly at the incongruent $(20.8 \mathrm{~s})$ and congruent stimuli (22.9 s) with the difference between the two measures not statistically different from zero $\left(t_{22}=0.528\right.$,

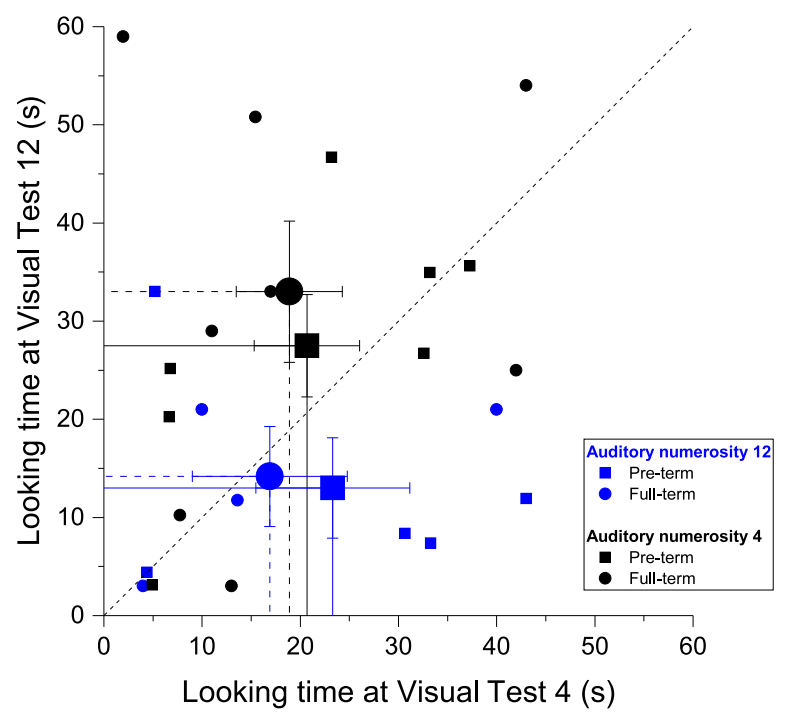

Figure 4. Looking time as a function of auditory condition in the first block of trials. Time (s) spent looking at visual numerosity four (abscissa) and twelve (ordinate) for the auditory stimulation conditions (4 sounds black, 12 sounds blue) and groups (preterm: squares, fullterm: circles). Small symbols report single subject data, bigger symbols report group average. Error bars reports \pm 1 s.e.m. 
$p=0.69$, one-tailed). This result confirms that the null effect found pooling both blocks and all participants together was driven by a null preferential looking behaviour in the second block.

\section{Discussion}

In the current experiment, we tested full-term (one day old) and preterm (2to 11-weeks-old) newborns with a modified crossmodal paradigm originally developed for full-term newborns (Coubart et al., 2014; Izard et al., 2009), to probe their sensitivity to numerosity across modalities (vision vs audition) and formats (sequential vs simultaneous items).

Overall, the results showed a very similar pattern of responses between groups. Full-term and preterm newborns' general looking behaviour was very similar and, more importantly, both showed the same signs of habituation to the auditory numerical quantities with a tendency to look longer at the visual numerical-incongruent stimuli. These results suggest that preterm children are likely to have, at term, a typical magnitude system.

While the original work (Izard et al., 2009) showed a preferential looking for the numerical congruent visual stimuli, here we found a preference for the incongruent (the classical habituation effect) between sequential items across two modalities (vision and audition). While we do not have obvious reasons for this discrepancy (see the limitations section), this is not the first time that crossmodal studies in infants have yielded discordant results. Leibovich et al. (2017) have recently reviewed many of these inconsistencies and raised doubts about the generalizability of crossmodal paradigm results in newborns. The authors suggested that newborns can discriminate between different quantitative dimensions at birth and that this ability may include numerosity but also other nonnumeric characteristics that covary with stimulus numerosity. According to the authors, newborns can abstract the notion of 'more' or 'less', that often is implicitly shared by item numerosity. Here, during the auditory stimulation, numerosity covaried with temporal frequency as well as with the duration of each sound sequence, while in the visual test numerosity covaried with summed luminance and with the total surface occupied by the array. The current results thus suggest that newborns were able to generalize some of these parameters, or the combination of them, across senses. Even if here we have not replicated the direction of the effect originally found by Izard et al. (2009) both studies showed a clear asymmetry in looking time as a function of the magnitude's congruency, confirming the ability to generalize quantities across senses. Our results add to this, showing that also preterm newborns, a population at risk of developing deficits in parietal areas known to play a key role in magnitude perception and numerical cognition (Arsalidou and Taylor, 
2011; Arsalidou et al., 2018; Bueti and Walsh, 2009; Castaldi et al., 2019; Harvey and Dumoulin, 2017; Harvey et al., 2013, 2015; Piazza and Eger, 2016), are also capable of abstracting quantitative dimensions. Another difficulty for the interpretation of our data arose from the poor spatial and temporal perceptual resolution of the newborns. Spatial acuity at birth is about 1 cycle/degree and temporal acuity around $4 \mathrm{~Hz}$ in newborns (Braddick and Atkinson, 2011; Dobson and Teller, 1978; Fiorentini and Trimarchi, 1992). For visual stimuli presented close and at high numerosity, the stimuli appeared blurred to the newborn and this might generate a bias towards higher numerosity. The minimum edge-to-edge distance between the visual objects used here was on average $1.5^{\circ}$, above newborns' visual acuity. However, it could happen, almost exclusively in the condition of higher numbers (N12), that two elements were less than $1^{\circ}$ apart and therefore below the newborns' acuity. The refresh of the visual displacement was at the low frequency of $1 \mathrm{~Hz}$, above newborns' temporal acuity. The low visual acuity at birth can thus increase the likelihood that visual objects are not always perceived as distinct units but sometimes fused together, probably giving weight to non-numerical features, such as covered area (for a critical review see Leibovich et al., 2017). Here we cannot completely exclude this possibility. That numerosity perception interacts with other non-numerical features is indisputable. These interactions do not dispute the existence of a numerical system. However, they suggest that, when possible and useful, numerical and nonnumerical parameters can be jointly used to extract numerosity. This issue is perhaps even more crucial in experiments with newborns.

The crossmodal habituation effect detected here could thus be contaminated by overall area and density perception. However, it is important to note that this caveat does not affect the conclusions of the current study: whatever the mechanisms are, they are intact in preterm newborns. As both numerosity, density and the area perception strongly engage the parietal cortex (Harvey and Dumoulin, 2017; Harvey et al., 2013, 2015), our data suggest that in our preterm infants parietal areas are maturing along a typical trajectory. Similar conclusions can be drawn on the crossmodal ability of habituation: preterm newborns have the typical ability to abstract different sensory cues across senses.

Although the crossmodal (vision-audition) and crossformat (temporal sequences-spatial arrays) nature of the habituation effect described here was particularly surprising, many previous studies have demonstrated that humans have the ability to perceive multisensory coherence at birth (for a review see Lewkowicz, 2014). For example, newborns' looking behaviour to light patches changes whether a previous sound is played or not (Lewkowicz and Turkewitz, 1981), they can learn to associate arbitrary objects and sounds (Slater et al., 1997), and they are able to perceive audio-visual intensity 
equivalence (Lewkowicz and Turkewitz, 1980). Probably more relevant to the current findings, newborns can even build expectations about magnitude changes, suggesting that early in life numerosity is intrinsically correlated with other magnitudes (de Hevia et al., 2014). In this latter experiment, the authors habituated newborns to pairs of magnitudes, for example a short or long line associated with few (six) or many (eighteen) sounds. Newborns were than tested with new pairs, in which the number of sounds and the line length could be increased or decreased. In some trials both number and length increased, in others they changed in the opposite direction. The results showed that newborns preferred congruent changes in the two dimensions. Similar results were also achieved by coupling temporal duration and numerosity of stimuli. The authors concluded by suggesting that the predisposition to connect continuous dimensions is present at birth, before sensory experience provided by the environment.

To summarize, these and other studies suggest that early crossmodal interactions are acting at birth. Multisensory processes have been suggested to play a fundamental role in scaffolding perception, cognition, learning, and behaviour (Murray et al., 2016) with a system able to match crossmodal information. This would provide a behavioural and perceptual advantage, such as faster and more accurate detection, localization, and discrimination of upcoming stimuli (Stein, 2012; Stein and Meredith, 1993). The current results suggest that this ecologically relevant ability is preserved in preterm newborns.

Despite still being controversial, it has been suggested that numerosity plays a role in the development of symbolic math abilities (Halberda et al., 2008; Piazza, 2010). Interestingly, even if many studies investigated preterm symbolic math learning proficiency (listed in the introduction), very few addressed the integrity of the system underlying numerosity perception in preterm children. Moreover, as there are no available data for children younger than five years old, the lack of data in newborns is limiting our understanding of the mechanisms. Moreover, the few studies available provided contradictory evidence, with four studies detecting worse performance among preterm born children (Guarini et al., 2014; Hellgren et al., 2013; Libertus et al., 2017; Simms et al., 2013) and two showing no differences (Guarini et al., 2006; Tinelli et al., 2015). To probe the numerosity system, the available studies employed different techniques (dot counting, dot comparison, number line) and performance parameters (accuracy, precision, reaction times, total error), making it difficult to draw general conclusions. Furthermore, across studies the preterm groups presented different clinical characteristics, such as gestational age (GA) and birth weight for example, and many had received different amounts and different types of special education between birth and the age of the assessments (often not detailed in the articles). Overall, the available data suggests that samples with lower gestation age differed more markedly from 
the full-term controls. Three of the four studies detecting significant differences between groups specifically included extremely preterm children (GA < 27 weeks; Hellgren et al., 2013; Libertus et al., 2017; Simms et al., 2013). The other three available studies, two of which showed no group differences (Guarini et al., 2006; Tinelli et al., 2015), applied less restrictive inclusion criteria, recruiting subjects with higher and more heterogeneous GA values. This suggests that only children born extremely preterm may show an atypical number sense. As our preterm sample did not include very high-risk infants (seven with GA $\geqslant 32$; all the others, GA $>28$ ), the results cannot be generalized to very extreme preterm populations $(\mathrm{GA}<27)$ and suggest further studies including very extreme preterm infants.

However, the idea that preterm babies are born with a typical numerosity system seems to conflict with the evidence that this population is classically characterized by a higher incidence of school difficulties related to math learning in very preterm children (for a meta-analysis, see Aarnoudse-Moens et al., 2009; Twilhaar et al., 2018). Indeed, studies on dyscalculic children often reported associated poor performance in many numerosity tasks (Butterworth, 2018; Dehaene, 2011) also related to parietal dysfunctions (Butterworth et al., 2011; Price et al., 2007), suggesting a specific aetiology linked to the inadequate development of this perceptual system (for different accounts see De Smedt and Gilmore, 2011; Landerl and Kölle, 2009; Rousselle and Noël, 2007; Szucs et al., 2013). This apparent contradiction, however, can be taken as an indication for a possible different aetiology underlying the arithmetic difficulties encountered in dyscalculic full-term subjects and those encountered by preterm children. This possibility has been interestingly advanced by recent studies suggesting that, while developmental dyscalculia among fullterms may derive from domain-specific deficits in the area of numbers and numerical quantities, the mathematical difficulties in the preterm population may be much more related to deficient domain-general functions, such as visuospatial processing, working memory and attention (Simms et al., 2015; van Veen et al., 2019). In line with this, a previous study focusing on schoolage preterms showed a profound visuospatial attentional deficit accompanied by a completely spared numerosity processing (Tinelli et al., 2015). This last study also suggested that not all the parietal functions have the same degree of vulnerability in this population and that the numerosity system could be particularly resistant. This issue has obvious implications for the design and management of math interventions in the preterm population, encouraging the targeting of domain-general functions in addition to basic numerical processing. 


\section{Limitations}

Together with the possible confounding role of nonnumerical parameters as well as the conflicting evidence on the link between numerosity perception and symbolic arithmetical abilities, the current study also has others obvious limitations. Studies on newborns are notoriously challenging, let alone studies with preterm neonates, and so we were only able to test a relatively small sample size (12 participants for each sample). While the sample size is adequate to compare the full-term and the pre-term abilities, which was the main aim of the protocol, it does not allow us to draw a complete conclusion on the habituation effect. The statistical power of the current study reached significance using a one-tailed $t$-test, on the assumption that habituation is the most common effect observed in infant looking behaviour. The Bayes factor of 2.8 supports the result, but does not allow for decisive rejection of H0. The results of the current study were obtained with an experimental paradigm similar to that of Izard et al. (2009) but, as discussed above, we found the effect in the opposite direction (habituation rather than assimilation). We do not have any obvious explanation for this discrepancy, and new replications studies are needed. Moreover, here we tested infants with only one pair of numerosities (4 vs 12 , ratio 1:3), which perhaps was too coarse to measure fine differences in acuity. Perhaps a difference between the preterm and full-term infants would emerge if they were tested with smaller numerical ratios. Finally, considering the current scarce and contradictory literature on numerosity perception in preterm children, caution is required in interpreting our results in support of a typical developmental trajectory of parietal areas in pre-term infants. Despite all the limitations, we believe that this study represents a valuable starting point, showing that crossmodal quantity perception in neonates born preterm and at term is similar.

\section{Acknowledgements}

We would particularly like to thank Veronique Izard for her invaluable support in the design of this experiment as well as in the interpretation of the results.

\section{Funding}

This research was funded by the European Union's Horizon 2020 research and innovation programmes ERC Advanced Grant number 832813 (GenPercept) and by the Italian Ministry of Education, University, and Research PRIN2017 programme, Grant numbers 2017XBJN4F and 2017SBCPZY. 


\section{References}

Aarnoudse-Moens, C. S. H., Weisglas-Kuperus, N., van Goudoever, J. B. and Oosterlaan, J. (2009). Meta-analysis of neurobehavioral outcomes in very preterm and/or very low birth weight children, Pediatrics 124, 717-728. DOI:10.1542/peds.2008-2816.

Aarnoudse-Moens, C. S. H., Oosterlaan, J., Duivenvoorden, H. J., van Goudoever, J. B. and Weisglas-Kuperus, N. (2011). Development of preschool and academic skills in children born very preterm, J. Pediatr. 158, 51-56. DOI:10.1016/j.jpeds.2010.06.052.

Anderson, P. J., De Luca, C. R., Hutchinson, E., Spencer-Smith, M. M., Roberts, G., Doyle, L. W. and Victorian Infant Collaborative Study Group (2011). Attention problems in a representative sample of extremely preterm/extremely low birth weight children, Dev. Neuropsychol. 36, 57-73. DOI:10.1080/87565641.2011.540538.

Anobile, G., Cicchini, G. M., Gasperini, F. and Burr, D. C. (2018a). Typical numerosity adaptation despite selectively impaired number acuity in dyscalculia, Neuropsychologia 120, 43-49. DOI:10.1016/j.neuropsychologia.2018.10.006.

Anobile, G., Arrighi, R., Castaldi, E., Grassi, E., Pedonese, L., Moscoso, P. A. M. and Burr, D. C. (2018b). Spatial but not temporal numerosity thresholds correlate with formal math skills in children, Dev. Psychol. 54, 458-473. DOI:10.1037/dev0000448.

Arsalidou, M. and Taylor, M. J. (2011). Is $2+2=4$ ? Meta-analyses of brain areas needed for numbers and calculations, Neuroimage 54, 2382-2393. DOI:10.1016/j.neuroimage.2010.10. 009.

Arsalidou, M., Pawliw-Levac, M., Sadeghi, M. and Pascual-Leone, J. (2018). Brain areas associated with numbers and calculations in children: meta-analyses of fMRI studies, Dev. Cogn. Neurosci. 30, 239-250. DOI:10.1016/j.den.2017.08.002.

Atkinson, J. and Braddick, O. (2007). Visual and visuocognitive development in children born very prematurely, Prog. Brain Res. 164, 123-149. DOI:10.1016/S0079-6123(07)64007-2.

Braddick, O. and Atkinson, J. (2011). Development of human visual function, Vision Res. 51, 1588-1609. DOI:10.1016/j.visres.2011.02.018.

Braddick, O., Atkinson, J. and Wattam-Bell, J. (2003). Normal and anomalous development of visual motion processing: motion coherence and 'dorsal-stream vulnerability', Neuropsychologia 41, 1769-1784. DOI:10.1016/s0028-3932(03)00178-7.

Bueti, D. and Walsh, V. (2009). The parietal cortex and the representation of time, space, number and other magnitudes, Philos. Trans. R. Soc. Lond. B Biol. Sci. 364, 1831-1840. DOI:10. 1098/rstb.2009.0028.

Butterworth, B. (2018). Dyscalculia: from Science to Education. Routledge, Nedw York, NY, USA.

Butterworth, B. and Walsh, V. (2011). Neural basis of mathematical cognition, Curr. Biol. 21, R618-R621. DOI:10.1016/j.cub.2011.07.005.

Butterworth, B., Varma, S. and Laurillard, D. (2011). Dyscalculia: from brain to education, Science 332, 1049-1053. DOI:10.1126/science.1201536.

Castaldi, E., Piazza, M., Dehaene, S., Vignaud, A. and Eger, E. (2019). Attentional amplification of neural codes for number independent of other quantities along the dorsal visual stream, Elife 8, e45160. DOI:10.7554/eLife.45160.

Castelli, F., Glaser, D. E. and Butterworth, B. (2006). Discrete and analogue quantity processing in the parietal lobe: a functional MRI study, Proc. Natl Acad. Sci. U. S. A. 103, 4693-4698. DOI:10.1073/pnas.0600444103. 
Chen, Q. and Li, J. (2014). Association between individual differences in non-symbolic number acuity and math performance: a meta-analysis, Acta Psychol. (Amst.) 148, 163-172. DOI:10. 1016/j.actpsy.2014.01.016.

Cicchini, G. M., Anobile, G. and Burr, D. C. (2019). Spontaneous representation of numerosity in typical and dyscalculic development, Cortex 114, 151-163. DOI:10.1016/j.cortex.2018. 11.019 .

Coubart, A., Izard, V., Spelke, E. S., Marie, J. and Streri, A. (2014). Dissociation between small and large numerosities in newborn infants, Dev. Sci. 17, 11-22. DOI:10.1111/desc.12108.

Dakin, S. C., Tibber, M. S., Greenwood, J. A., Kingdom, F. A. and Morgan, M. J. (2011). A common visual metric for approximate number and density, Proc. Natl Acad. Sci. U. S. A. 108, 19552-19557. DOI:10.1073/pnas.1113195108.

de Hevia, M. D., Izard, V., Coubart, A., Spelke, E. S. and Streri, A. (2014). Representations of space, time, and number in neonates, Proc. Natl Acad. Sci. U. S. A. 111, 4809-4813. DOI:10. 1073/pnas.1323628111.

de Hevia, M. D., Castaldi, E., Streri, A., Eger, E. and Izard, V. (2017). Perceiving numerosity from birth, Behav. Brain Sci. 40, e169. DOI:10.1017/s0140525x16002090.

De Smedt, B. and Gilmore, C. K. (2011). Defective number module or impaired access? Numerical magnitude processing in first graders with mathematical difficulties, J. Exp. Child Psychol. 108, 278-292. DOI:10.1016/j.jecp.2010.09.003.

Dehaene, S. (2011). The Number Sense: How the Mind Creates Mathematics. Oxford University Press, New York, NY, USA.

Dobson, V. and Teller, D. Y. (1978). Visual acuity in human infants: a review and comparison of behavioral and electrophysiological studies, Vision Res. 18, 1469-1483. DOI:10.1016/00426989(78)90001-9.

Efron, B. and Tibshirani, R. J. (1993). An Introduction to the Bootstrap. Chapman and Hall, Boca Raton, FL, USA.

Faul, F., Erdfelder, E., Lang, A.-G. and Buchner, A. (2007). G*Power 3: a flexible statistical power analysis program for the social, behavioral, and biomedical sciences, Behav Res Methods 39, 175-191. DOI:10.3758/bf03193146.

Fiorentini, A. and Trimarchi, C. (1992). Development of temporal properties of pattern electroretinogram and visual evoked potentials in infants, Vision Res. 32, 1609-1621. DOI:10. 1016/0042-6989(92)90154-b.

Gebuis, T. and Reynvoet, B. (2012). The interplay between nonsymbolic number and its continuous visual properties, J. Exp. Psychol. Gen. 141, 642-648. DOI:10.1037/a0026218.

Gebuis, T., Cohen Kadosh, R. and Gevers, W. (2016). Sensory-integration system rather than approximate number system underlies numerosity processing: a critical review, Acta Psychol. (Amst.) 171, 17-35. DOI:10.1016/j.actpsy.2016.09.003.

Guarini, A., Sansavini, A., Giovanelli, G., Alessandroni, R., Faldella, G., Ansari, D. and Karmiloff-Smith, A. (2006). Basic numerical processes in preterms, World J. Pediatr. 2, 102-108.

Guarini, A., Sansavini, A., Fabbri, M., Alessandroni, R., Faldella, G. and Karmiloff-Smith, A. (2014). Basic numerical processes in very preterm children: a critical transition from preschool to school age, Early Hum. Dev. 90, 103-111. DOI:10.1016/j.earlhumdev.2013.11. 003. 
Guzzetta, A., Mazzotti, S., Tinelli, F., Bancale, A., Ferretti, G., Battini, R., Bartalena, L., Boldrini, A. and Cioni, G. (2006). Early assessment of visual information processing and neurological outcome in preterm infants, Neuropediatrics 37, 278-285. DOI:10.1055/s2006-955929.

Guzzetta, A., Tinelli, F., Del Viva, M. M., Bancale, A., Arrighi, R., Pascale, R. R. and Cioni, G. (2009). Motion perception in preterm children: role of prematurity and brain damage, Neuroreport 20, 1339-1343. DOI:10.1097/WNR.0b013e328330b6f3.

Halberda, J., Mazzocco, M. M. and Feigenson, L. (2008). Individual differences in non-verbal number acuity correlate with maths achievement, Nature 455, 665-668. DOI:10.1038/ nature 07246.

Harvey, B. M. and Dumoulin, S. O. (2017). Can responses to basic non-numerical visual features explain neural numerosity responses?, Neuroimage 149, 200-209. DOI:10.1016/ j.neuroimage.2017.02.012.

Harvey, B. M., Klein, B. P., Petridou, N. and Dumoulin, S. O. (2013). Topographic representation of numerosity in the human parietal cortex, Science 341, 1123-1126. DOI:10.1126/ science. 1239052.

Harvey, B. M., Fracasso, A., Petridou, N. and Dumoulin, S. O. (2015). Topographic representations of object size and relationships with numerosity reveal generalized quantity processing in human parietal cortex, Proc. Natl Acad. Sci. U. S. A. 112, 13525-13530. DOI:10.1073/ pnas. 1515414112 .

Hellgren, K., Halberda, J., Forsman, L., Adén, U. and Libertus, M. (2013). Compromised approximate number system acuity in extremely preterm school-aged children, Dev. Med. Child Neurol. 55, 1109-1114. DOI:10.1111/dmcn.12206.

Holloway, I. D. and Ansari, D. (2010). Developmental specialization in the right intraparietal sulcus for the abstract representation of numerical magnitude, J. Cogn. Neurosci. 22, 26272637. DOI:10.1162/jocn.2009.21399.

Isaacs, E. B., Edmonds, C. J., Lucas, A. and Gadian, D. G. (2001). Calculation difficulties in children of very low birthweight: a neural correlate, Brain 124, 1701-1707. DOI:10.1093/ brain/124.9.1701.

Izard, V., Sann, C., Spelke, E. S. and Streri, A. (2009). Newborn infants perceive abstract numbers, Proc. Natl Acad. Sci. U. S. A. 106, 10382-10385. DOI:10.1073/pnas.0812142106.

Kooiker, M. J. G., Swarte, R. M. C., Smit, L. S. and Reiss, I. K. M. (2019). Perinatal risk factors for visuospatial attention and processing dysfunctions at 1 year of age in children born between 26 and 32 weeks, Early Hum. Dev. 130, 71-79. DOI:10.1016/j.earlhumdev. 2019.01.015.

Landerl, K. and Kölle, C. (2009). Typical and atypical development of basic numerical skills in elementary school, J. Exp. Child Psychol. 103, 546-565. DOI:10.1016/j.jecp.2008.12.006.

Leibovich, T., Katzin, N., Harel, M. and Henik, A. (2017). From "sense of number" to "sense of magnitude": the role of continuous magnitudes in numerical cognition, Behav. Brain Sci. 40, e164. DOI:10.1017/s0140525x16000960.

Lewkowicz, D. J. (2014). Early experience and multisensory perceptual narrowing, Dev. Psychobiol. 56, 292-315. DOI:10.1002/dev.21197.

Lewkowicz, D. J. and Turkewitz, G. (1980). Cross-modal equivalence in early infancy: auditory-visual intensity matching, Dev. Psychol. 16, 597-607. DOI:10.1037/0012-1649. 16.6.597. 
Lewkowicz, D. J. and Turkewitz, G. (1981). Intersensory interaction in newborns: modification of visual preferences following exposure to sound, Child Dev. 52, 827-832. DOI:10.2307/ 1129083.

Libertus, M. E., Forsman, L., Adén, U. and Hellgren, K. (2017). Deficits in approximate number system acuity and mathematical abilities in 6.5-year-old children born extremely preterm, Front. Psychol. 8, 1175. DOI:10.3389/fpsyg.2017.01175.

Lyons, I. M., Ansari, D. and Beilock, S. L. (2012). Symbolic estrangement: evidence against a strong association between numerical symbols and the quantities they represent, J. Exp. Psychol. Gen. 141, 635-641. DOI:10.1037/a0027248.

MacKay, T. L., Jakobson, L. S., Ellemberg, D., Lewis, T. L., Maurer, D. and Casiro, O. (2005). Deficits in the processing of local and global motion in very low birthweight children, $\mathrm{Neu}$ ropsychologia 43, 1738-1748. DOI:10.1016/j.neuropsychologia.2005.02.008.

Mazzocco, M. M. M., Feigenson, L. and Halberda, J. (2011). Impaired acuity of the approximate number system underlies mathematical learning disability (dyscalculia), Child Dev. $\mathbf{8 2}$, 1224-1237. DOI:10.1111/j.1467-8624.2011.01608.x.

Murray, M. M., Lewkowicz, D. J., Amedi, A. and Wallace, M. T. (2016). Multisensory processes: a balancing act across the lifespan, Trends Neurosci. 39, 567-579. DOI:10.1016/j. tins.2016.05.003.

Nieder, A. and Dehaene, S. (2009). Representation of number in the brain, Annu. Rev. Neurosci. 32, 185-208. DOI:10.1146/annurev.neuro.051508.135550.

Núñez, R. E. (2017). Is there really an evolved capacity for number?, Trends Cogn. Sci. 21, 409-424. DOI:10.1016/j.tics.2017.03.005.

Padilla, N., Alexandrou, G., Blennow, M., Lagercrantz, H. and Ådén, U. (2015). Brain growth gains and losses in extremely preterm infants at term, Cereb. Cortex 25, 1897-1905. DOI:10. 1093/cercor/bht431.

Piazza, M. (2010). Neurocognitive start-up tools for symbolic number representations, Trends Cogn. Sci. 14, 542-551. DOI:10.1016/j.tics.2010.09.008.

Piazza, M. and Eger, E. (2016). Neural foundations and functional specificity of number representations, Neuropsychologia 83, 257-273. DOI:10.1016/j.neuropsychologia.2015.09.025.

Piazza, M., Facoetti, A., Trussardi, A. N., Berteletti, I., Conte, S., Lucangeli, D., Dehaebe, S. and Zorzi, M. (2010). Developmental trajectory of number acuity reveals a severe impairment in developmental dyscalculia, Cognition 116, 33-41. DOI:10.1016/j.cognition.2010.03.012.

Price, G. R., Holloway, I., Räsänen, P., Vesterinen, M. and Ansari, D. (2007). Impaired parietal magnitude processing in developmental dyscalculia, Curr. Biol. 17, R1042-R1043. DOI:10. 1016/j.cub.2007.10.013.

Rousselle, L. and Noël, M.-P. (2007). Basic numerical skills in children with mathematics learning disabilities: a comparison of symbolic vs non-symbolic number magnitude, Cognition 102, 361-395. DOI:10.1016/j.cognition.2006.01.005.

Schneider, M., Beeres, K., Coban, L., Merz, S., Schmidt, S. S., Stricker, J. and De Smedt, B. (2017). Associations of non-symbolic and symbolic numerical magnitude processing with mathematical competence: a meta-analysis, Dev. Sci. 20, e12372. DOI:10.1111/desc.12372.

Simms, V., Gilmore, C., Cragg, L., Marlow, N., Wolke, D. and Johnson, S. (2013). Mathematics difficulties in extremely preterm children: evidence of a specific deficit in basic mathematics processing, Pediatr. Res. 73, 236-244. DOI:10.1038/pr.2012.157. 
Simms, V., Gilmore, C., Cragg, L., Clayton, S., Marlow, N. and Johnson, S. (2015). Nature and origins of mathematics difficulties in very preterm children: a different etiology than developmental dyscalculia, Pediatr. Res. 77, 389-395. DOI:10.1038/pr.2014.184.

Slater, A., Brown, E. and Badenoch, M. (1997). Intermodal perception at birth: newborn infants' memory for arbitrary auditory-visual pairings, Early Dev. Parent. 6, 99-104. DOI:10.1002/ (sici)1099-0917(199709/12)6:3/4<99::Aid-edp149>3.0.Co;2-m.

Starr, A., Libertus, M. E. and Brannon, E. M. (2013). Number sense in infancy predicts mathematical abilities in childhood, Proc. Natl Acad. Sci. U. S. A. 110, 18116-18120. DOI:10. 1073/pnas.1302751110.

Stein, B. E. (2012). The New Handbook of Multisensory Processing. MIT Press, Cambridge, MA, USA.

Stein, B. E. and Meredith, M. A. (1993). Cognitive Neuroscience. The Merging of the Senses. MIT Press, Cambridge, MA, USA.

Szucs, D., Devine, A., Soltesz, F., Nobes, A. and Gabriel, F. (2013). Developmental dyscalculia is related to visuo-spatial memory and inhibition impairment, Cortex 49, 2674-2688. DOI:10.1016/j.cortex.2013.06.007.

Taylor, H. G., Espy, K. A. and Anderson, P. J. (2009b). Mathematics deficiencies in children with very low birth weight or very preterm birth, Dev. Disabil. Res. Rev. 15, 52-59. DOI:10. 1002/ddrr.51.

Taylor, N. M., Jakobson, L. S., Maurer, D. and Lewis, T. L. (2009a). Differential vulnerability of global motion, global form, and biological motion processing in full-term and preterm children, Neuropsychologia 47, 2766-2778. DOI:10.1016/j.neuropsychologia.2009.06.001.

Tinelli, F., Anobile, G., Gori, M., Aagten-Murphy, D., Bartoli, M., Burr, D. C., Cioni, G. and Morrone, M. C. (2015). Time, number and attention in very low birth weight children, Neuropsychologia 73, 60-69. DOI:10.1016/j.neuropsychologia.2015.04.016.

Twilhaar, E. S., de Kieviet, J. F., Aarnoudse-Moens, C. S., van Elburg, R. M. and Oosterlaan, J. (2018). Academic performance of children born preterm: a meta-analysis and meta-regression, Arch. Dis. Child Fetal Neonatal. Ed. 103, F322-F330. DOI:10.1136/ archdischild-2017-312916.

van de Weijer-Bergsma, E., Wijnroks, L. and Jongmans, M. J. (2008). Attention development in infants and preschool children born preterm: a review, Infant Behav. Dev. 31, 333-351. DOI:10.1016/j.infbeh.2007.12.003.

van Veen, S., van Wassenaer-Leemhuis, A. G., van Kaam, A. H., Oosterlaan, J. and AarnoudseMoens, C. S. H. (2019). Visual perceptive skills account for very preterm children's mathematical difficulties in preschool, Early Hum. Dev. 129, 11-15. DOI:10.1016/j.earlhumdev. 2018.12.018.

Volpe, J. J. (2009). The encephalopathy of prematurity — brain injury and impaired brain development inextricably intertwined, Semin. Pediatr. Neurol. 16, 167-178. DOI:10.1016/j.spen. 2009.09.005.

World Health Organization (2018). Preterm birth. Retrieved from https://www.who.int/newsroom/fact-sheets/detail/preterm-birth. 